\title{
ЗНАЧИТЕЛЬНЫЙ ВКЛАД ОМАР ХАЙЯМА В ОБЛАСТИ МАТЕМАТИКИ
}

\author{
Аликенова К.Н., к.ф.н., ассоциированный профессор \\ Осипова Е.В., магистрант 1 курса, специальности «Математика» \\ Жетысуский университет им. И.Жансугурова, г. Талдыкорган \\ E-mail: k-alikenova@mail.ru,osipova_ekaterina99@mail.ru
}

\begin{abstract}
Цель исследования: определить основные достижения и вклад Омар Хайяма в области математики. В данной статье акцентируется небольшое внимание на жизнедеятельность ученого и поэта прошлого тысячилетия и в большей степени научных достижений в области естественных и технических наук. Научная новизна заключается в внутридисииплинарном рассмотрении математических вопросов в трудах древнегреческого ученого Омар Хайяма. В результате исследования было выделено несколько научных достижений и исследований в области математики, которые по сей день имеют большую значимость и решение некоторых математических задач невозможно без их применения.

Ключевые слова: образование, наука, естественные и точные науки, математика, алгебра, арифметика, геометрия, алгебраист, математический трактат, уравнение, алгебраическое уравнение, постулат, основные постулаты Евклида, учение о числе.
\end{abstract}

Зерттеудің мақсаты: Омар Хайямның математика саласындавы негізгі жетістіктері мен үлесін анықтау. Бұл маққалада өткен мыңџжылдықтавы валылм мен ақынның өмірі мен жаратылыстану және техникалық вылымдар саласындавы вылыли жетістіктерге аз көңіл бөлінеді. Ғылыми жаңалық-ежелгі грек выльлмы Омар Хайямның еңбектеріндегі математикальққ мәселелерді пәнаральққ қарастыру. Зерттеу нәтижесінде математика саласындавы бірнеше вылыми жетістіктер мен зерттеулер анықталды, олар бүгінгі күнге дейін үлкен маңыьзва ие және кейбір математикалық есептерді оларды қ̧олданбай шешу мүмкін емес

Тірек сөздер: білім, вылым, жаратылыстану және нақты вылымдар, математика, алгебра, арифметика, геометрия, алгебра, математикалық трактат, теңдеу, алгебральқ теңцеу, постулат, Евклидтің негізгі постулаттары, сан тураль ілім.

The purpose of the study: to identify the main achievements and contributions of Omar Khayyam in the field of mathematics. This article focuses a little attention on the vital activity of the scientist and poet of the last millennium and, to a greater extent, scientific achievements in the field of natural and technical sciences. The scientific novelty lies in the interdisciplinary consideration of mathematical issues in the works of the ancient Greek scientist Omar Khayyam. As a result of the research, several scientific achievements and research in the field of mathematics have been identified, which to this day are of great importance and the solution of some mathematical problems is impossible without their application.

Key words: education, science, natural and exact sciences, mathematics, algebra, arithmetic, geometry, algebra, mathematical treatise, equation, algebraic equation, postulate, basic postulates of Euclid, the doctrine of number.

Развитие математических наук берет свое начало еще в древности и подразделяется на несколько этапов. Многие ученые проводили большое количество исследований различных проблем математики, а так же создание некоторых математических дисциплин, которые имеют значительное применение не только в решении математических задач, но и в решении некоторых бытовых вопросов. 
Многие источники связывают развитие математики с такими именами как: Архимед, Л.Феррари, Ньютон, Лейбниц, Лагранж, Эйлер и другие. Но все знают то, что в прошлом тысячилетии значительный вклад в развитие математики был сделан центральноазиатским философом Гиясаддин Абуль Фатх ибн Ибрахим Омар Хайям Нишапури (1048-1123), который родился на Востоке Ирана в городе Нишапур. В первую очередь Омар Хайям знаменит своими четверостишиями «Рубаи», полными мудрости и тонкостью изречения, а так же отличным обладанием арабского языка, арабской литературы и владением основами стихосложения. Зная арабский язык, ознакомившись с достижениями античной науки, трудов Аристотеля, Архимеда и Евклида, полностью перевел их на арабский язык. Кроме поэзии и хорошего владения языками Омар Хайям обладал значительным объемом информации естественных и точных наук. Написал трактаты по механике, философии, географии и музыке в дополнение к своим прорывным работам по алгебре и астрономии.

Так же Омар Хайям был талантлив в астрологии и врачеванием (диагностика некоторых болезней, которая проводится посредством задавания вопросов), профессионально изучал теорию музыки. Омар Хайям работал в крупнейших научных и культурных центрах Средней Азии - Балхе, Самарканде, Исфахане, Бухаре. Его приглашали ко двору многие властители Востока. Отправной точкой для размышлений Хайяма была его основная область - математика. Он прекрасно знал о существовании упорядоченного мира чисел и измерений. Истины математики ведут к Богу. [1, с. 17].

Математические сочинения Омар Хайяма характеризуют его как выдающего ученого того периода. Он внес значительный вклад в развитие и становление алгебры. Хайям писал об алгебре следующее:

«Алгебра есть научное искусство. Ее предмет - это абсолютное число и измеримые величины, являющиеся неизвестными, но отнесенные к какой-нибудь известной вещи так, что их можно определить; это известная вещь есть количество или индивидуально определенное отношение, ик этой известной вещи приходят, анализируя условие задачи; 6 этом искусстве ищут соотношение, связывающие данные в задачах величины $c$ неизвестной, которая вылеуказанным образом составляет предмет алгебры. Совершенство этого искусства состочт в знании математических методов, с помощью которых можно осуществить упомянутые определения как числовых, так $u$ геометрических неизвестных... Алгебраические решения производятся лишь с помощью уравнений» [2, с.115]. Данное объяснение является одним из первых объяснений такой науки как алгебра и описывает алгебру как науку о нахождении и определении неизвестных величин, которые состоят в некоторых отношениях с известными величинами. Процесс нахождения неизвестных осуществляется с помощью составления и решения различного вида алгебраических уравнений и неравенств.

В возрасте 25 лет Хайям совершает свои самые первые научные открытия. Первый его математический трактат «Трудности арифметики», к сожалению, на данный момент не обнаружен, но из других работ известно то, что что он содержит сведения о разработанном им общем приеме извлечения корня любой степени с натуральным показателем «методом индийцев», т.е. с помощью правил $(a+b)^{2}$ и $(a+b)^{3}$. Основываясь на известных фактах, ученые предполагают, что Хайям открыл формулу возведения двучлена $a+b$ в степень $n$. (К сожалению, результаты работы математиков Востока были неизвестны в Европе до XVII в., поэтому их пришлось открывать заново.) Математический труд, благодаря которому он получил знаменитость и славу как алгебраисту: «Трактат о доказательствах проблем алгебры и ал-мукабалы» (1074 г.), написанный в 60-е годы одиннадцатого века в Самарканде. Данный трактат описывает теорию геометрических решений алгебраических уравнений. Омар Хайям самый первый ученый-алгебраист, который высказал мысль о том, что уравнения в третьей степени не имеют решения с помощью «свойств круга», применяя циркуль и линейку. Решение может быть найдено только с привлечением конических сечений.

Омар Хайям дал полную классификацию кубических уравнений, имеющих положительные корни. Он выделил основных 19 классов; из них 5 сводятся к линейным и 
квадратным ( $d x^{3}=c x^{2}, d x^{3}=b x$ и др.). Для остальных 14 классов $\left(d x^{3}=a, d x^{3}+b x=a\right.$ и т.д.) Хайям указал метод решения с помощью конических сечений - параболы, равносторонней гиперболы, окружности. В процессе решения вопроса о числе из 14 классов уравнений, Омар Хайям учитывал необходимые условия, накладываемые на коэффициенты уравнения [3, c.17]. Например, он указывал, что при любых значениях а и $\mathrm{b}$ уравнение $x^{3}+b x=a$ имеет единственный положительный корень. (Теория решения кубических уравнений с помощью конических сечений была развита в Европе в XVII в. Декартом и другими учеными, которые не были знакомы с трудами О. Хайяма.)

О.Хайям ставит задачу численного решения кубического уравнения как и квадратных, но признал, что все приложенные усилия в этой области были бесполезны: «Доказательство этих видов в том случае, когда предмет задачи есть абсолютное число, невозможно ни для нас, ни для кого из тех, кто владеет этим искусством. Может быть, кто-нибудь из тех, кто придет после нас, узнает это ... ». Решение в радикалах кубических уравнений нашли в XVI в. итальянские математики Ш. дель Ферро и Н. Тарталья.» Он первым ввел термин «иррациональные числа», создал новую теорию параллелей, некоторые его теоремы были «по существу тем же, что и первые теоремы неевклидовой геометрии Лобачевского и Римана». [1, с.18].

Основное содержание алгебры Хайяма является классификация видов уравнений, построение корней геометрическим методом и определение количества положительных решений уравнения. Уравнения здесь рассматриваются в общем виде, иначе говоря, с произвольными положительными коэффициентами, но выраженными словесно. В основу классификации заложены степень уравнения и число членов, расположенных в обеих частях уравнения. Всего рассматривалось 25 видов канонических видов, среди которых 6 были рассмотрены аль-Хорезми, остальные 5 приводятся к ним делением на неизвестное и 14, как упоминалось ранее, строятся с помощью конических сечений. Процесс решения квадратных уравнений не содержит чего-либо нового и поэтому сразу происходит переход к кубическим уравнениям. Вслед за древними, Омар Хайям строго соблюдает принцип однородности. Он, например, предупреждает, что, говоря о равенстве числа и поверхности, понимает под числом прямоугольник, одна из сторон которого есть число один, а другая взята соответственным образом.

Надо отметить, что математики того времени выражали уравнения словесно. Например, уравнение $x^{3}+b x=a$ выражалось фразой «куб и корни ровны числу». Корнями этого уравнения являются абсциссы точек пересечения кривых - окружности $\mathrm{x}^{2}+\mathrm{y}^{2}=$ и параболы.

Трактат О. Хайяма «Комментарии к трудным постулатам книги Евклида» (1077), состоящий из трех частей.

Первая часть посвящена теории параллельных линий. Стремясь доказать V постулат Евклида, Хайям сформулировал принцип, на котором основано его доказательство: «Две сходящиеся прямые пересекаются, и невозможно, чтобы две сходящиеся прямые сходились в направлении схождения». Эти утверждения равносильны V постулату. Кроме того, в первой части трактата рассматривается четырехугольник с двумя прямыми углами при основании и равными боковыми сторонами. Ученый исследовал численную величину двух других углов четырехугольника. Используя свой принцип, Омар Хайям опроверг гипотезу острого и тупого углов, а затем доказал V постулат.

О взаимосвязи геометрии с арифметикой Омар Хайям пишет так: «Геометрия нуждается в числах». Этим он превосходил Декарта, создавшего аналитическую геометрию.

Во второй и третий частях трактата «Комментарии к трудным постулатам книги Евклида» О. Хайям анализирует античную теорию отношений и учение о числе. Средневековый ученный внес значительный вклад и в создание понятия действительного числа. Понятие иррационального числа стало равноправным с числом рациональным [4, c.265]. 
Исходя из всего вышесказанного, труды центральноазиатского ученого Омар Хайяма принесли огромную пользу в развитие естественных и точных наук, а так же в развитие поэзии и в настоящее время его оценивают как важную фигуру в мире поэзии и науки. Многие его труды были переведены на все основные языки мира. Так же Хайям не только являлся отличным математиком и алгебраистом, но и отличным философом, астрономом, физиком и корановедом. Он страстно желал переустройства мира и делал для этого все, что в его силах: открывал законы природы, устремлял взгляд на звезды, вникал в тайны мироздания и помогал людям освобождаться от духовного рабства.

\section{ЛИТЕРАТУРА:}

1. Аликенова К., Касабек А. «Центральноазиатская наука Средневековья», Учебнометодическое пособие. - Талдыкорган 2019 г., стр. 30

2. Глейзер Г. И. История математики в школе VII-VIII кл. Пособие для учителей. -M.: Просвещение, 2008 г., стр. 115

3. А.Г. Карабаева «История и философия науки», Алматы 2019 г., стр. 34

4. С.А.Лебедев «Философия науки», Москва, 2015 г., стр. 265 